\title{
EXPERIÊNCIA MATERNA DE PERDA DE UM FILHO COM CÂNCER INFANTIL: UM ESTUDO FENOMENOLÓGICO
}

\author{
Maternal experience of loss of a child with cancer: a phenomenological study \\ Experiencia materna de pérdida de un hijo con cáncer infantil: un estudio fenomenológico \\ Patricia Karla de Souza e Silva \\ Symone Fernandes de Melo
}

\begin{abstract}
Resumo: A morte em decorrência de câncer infantil reflete um desfecho precoce da vida podendo provocar forte repercussão na existência da mãe, figura que, comumente, assume a maior parte das responsabilidades durante o adoecimento do filho. Reconhecendo a relevância do tema, nesta pesquisa busca-se compreender a experiência de uma mãe que vivenciou a perda de um filho em decorrência de câncer infantil. Trata-se de uma pesquisa qualitativa, fenomenológica, que tem como método a "narrativa", obtida a partir de entrevista semiestruturada. A pesquisa, configurada como estudo de caso, contou com a participação de uma mãe e foi desenvolvida numa organização não governamental de apoio à criança com câncer, localizada na cidade do Natal-RN. A proposta de análise tem por fundamento a hermenêutica heideggeriana. Desvelaram-se três eixos temáticos: história prévia, adoecimento infantil e suas repercussões; a rede de apoio e o cuidado; a perda e o depois: enfrentamento e significação. Conclui-se que a experiência do câncer infantil é capaz de aproximar cada mãe da ontológica sensação de desamparo humano, mobilizando mudanças, e que a garantia do cuidado, durante o processo de adoecimento e perda do filho, favorece uma vivência autêntica do luto e a abertura de novas possibilidades em suas vidas.
\end{abstract}

Palavras-chave: Câncer infantil; Morte; Luto materno; Fenomenologia; Analítica existencial.

Abstract: The death of a child due to cancer reflects a premature end of life and can cause strong repercussions to the mother who is the one that usually takes most responsibility during child's treatment. Recognizing the importance of the topic, this research seeks to understand the experience of a mother who experienced the loss of a child due to cancer. This is a qualitative, phenomenological research that uses a method called "narrative", which consists in a semi-structured interview. The research is set up as a case study, with the participation of one mother and was developed in a non-governmental organization that supports children with cancer, located in the city of Natal-RN. The proposed analysis is based Heideggerian hermeneutics. This study pointed to three themes: previous history, childhood illness and its repercussions; the network of support and care, and the loss and afterwards: coping and meaning. It is concluded that the experience of child cancer allows each mother to face ontological sense of human helplessness, mobilizing change and that the guarantee of care during the illness and loss of their sons, favors an authentic experience of mourning and the opening for new possibilities in their lives.

Keywords: Childhood cancer; Death; Motherly mourn; Phenomenology; Existential analytic.

Resumen: La muerte debido al cáncer infantil refleja en un resultado precoz de vida pudiendo provocar fuerte repercusión en la existencia de la madre, quien asume generalmente las mayores responsabilidades durante la enfermedad del hijo. Reconociendo la relevancia del tema, esta investigación busca comprender la experiencia de una madre que sufrió la pérdida de un hijo debido al cáncer infantil. Se trata de una investigación cualitativa, fenomenológica, que tiene como método la "narrativa”, obtenida por entrevista semiestructurada. La investigación, configurada como estudio del caso, contó con la participación de una madre y fue desarrollada en una organización no gubernamental de apoyo al niño con cáncer, ubicada en Natal-RN. La propuesta de análisis tiene por fundamento la hermenéutica heideggeriana. Se dio a conocer tres ejes temáticos: historia previa, enfermedad infantil y sus repercusiones; la red de apoyo y el cuidado; la pérdida y el después: enfrentamiento y significación. Se concluye que la experiencia del cáncer infantil es capaz de aproximar cada madre de la ontológica sensación de desamparo humano, movilizando cambios y que la garantía del cuidado durante el proceso de enfermedad y pérdida del hijo, favorece una autentica experiencia del luto y la apretura de nuevas posibilidades en sus vidas.

Palabras-clave: Cáncer infantil; Muerte; Luto materno; Fenomenología; Analítica existencial.

\section{Introdução}

O processo de morrer e o acontecimento da morte inscrevem-se nos âmbitos individual e social como dado inexorável, a partir de diferentes formas de interpretação, negociação e enfrentamento (Bellato \& Carvalho,
2005). Levando-se em consideração a complexa conjuntura de fatores que interferem na atribuição de sentidos e na expressão de comportamentos, é possível afirmar que a sociedade ocidental constitui-se como discípula e reprodutora de uma cultura na qual as atitudes construídas e aprendidas a respeito da morte refletem um posicio- 
namento majoritário de banimento e/ou negação (Ariès, 1975/1977; Elias, 2001).

Neste cenário, o lugar da doença crônica/mortal na infância instaura, inicialmente, um sentimento de frustração e pode vir a inaugurar, a posteriori, uma crise de sentido, que repercute como uma crise da própria vida (Hoffman, 1993). Em direção oposta a todos os argumentos solidamente elaborados em torno do fenômeno da morte, a possibilidade desta se concretizar na criança, de forma aleatória e inesperada, não interfere apenas no percurso daquele que se vai, mas, sobretudo, na vida daqueles que permanecem vivos (Carneiro, Souza \& Paula, 2009).

Dentro de um conjunto diversificado de patologias que podem surgir na infância, alguns estudos particularizam o lugar do câncer (Ortiz, 2003; Santos \& Gonçalves, 2008) a partir das repercussões negativas que ele ocasiona desde a sua origem até a sua conclusão (seja ela a cura ou a morte), bem como os impactos que ele produz individualmente em cada membro familiar.

Os últimos relatórios de organizações nacionais e internacionais confirmam que o câncer permanece dentre as principais patologias responsáveis pela morte de crianças, podendo ser qualificado como um sério problema de saúde pública mundial (Beltrão, Vasconcelos, Pontes \& Albuquerque, 2007; Instituto Nacional de Câncer José Alencar Gomes da Silva - INCA, 2011). No Brasil, desde a década de 1960, as neoplasias malignas, ao lado das doenças do aparelho circulatório, tornaram-se as principais causas de morte por doença na população. Quando analisados exclusivamente dentro do público infanto-juvenil, os óbitos por neoplasias situam-se entre as dez primeiras causas de morte, alcançando a primeira posição a partir dos cinco anos de idade, em meninos e meninas (INCA, 2011). Todo esse panorama estatístico acerca da realidade do câncer infantil ratifica, portanto, a ideia de que o fenômeno da morte não aparece somente como possibilidade (ameaça) de ocorrência em fases tardias da vida, confirmando sua presença de maneira factível e irremediável ao longo de toda a existência humana, inclusive na infância.

Conviver com a experiência da morte de outrem inaugura um fenômeno chamado de luto, processo frequentemente convencionado à perda irreversível de outro ser humano, ou seja, ao rompimento de um vínculo (Bowlby, 1985/2004; Franco, 2009; Parkes, 1972/1998). Para pais que atravessam a experiência da perda de um filho com câncer infantil, o processo de luto pode ser iniciado durante o próprio adoecimento (Teles, 2005), mas só se confirma após a partida definitiva da criança.

A maior parte dos estudos sobre câncer infantil enfatiza que a mãe tem sido a personagem que mais se envolve nos cuidados com o filho enfermo (Beltrão \& cols., 2007; Ortiz, 2003; Santos \& Gonçalves, 2008; Wegner \& Pedro, 2010). Figura histórica e culturalmente representada pela função de cuidar, ela reatualiza esse papel nos casos de adoecimento infantil, circunstância específica que acarretará um vasto número de transformações físicas, psicológicas, econômicas e sociais (Beck \& Lopes, 2007). Aquela que antes executava múltiplos papéis vê-se solicitada a priorizar o seu papel de mãe, focalizando suas atenções e cuidados sobre o filho com câncer.

Em um contexto atravessado por constantes rearranjos impostos pelo processo de tratamento da doença, o acontecimento da morte do filho representa a destituição do caráter dialético de uma relação singular, de modo irrevogável e pode provocar forte impacto na vida pessoal, conjugal/familiar e social da mãe (Beck \& Lopes, 2007; Wegner \& Pedro, 2010).

Considerando os breves apontamentos feitos acerca da morte e do luto, a constatação dos altos índices de mortalidade infantil em decorrência do câncer, o impacto singular desta patologia sobre aquela que tradicionalmente assume a prioridade dos cuidados com a criança e, reconhecendo a relevância destas informações, este estudo tem como objetivo compreender a experiência de uma mãe que perdeu seu filho em decorrência de câncer infantil, aproximando-se dos sentidos pessoais desta vivência por meio da perspectiva fenomenológico-existencial. Desta forma, pretende-se ampliar a compreensão do luto materno, vislumbrando alternativas de acompanhamento nesse caminho, considerando como o problema é vivido por elas, mulheres e mães, em seu estar-no-mundo.

\section{Método}

\subsection{Pesquisa fenomenológica}

O presente estudo confirma-se segundo os moldes de um delineamento qualitativo, com enfoque exploratório e compreensivo (Minayo, 2000), na modalidade de estudo de caso. Segundo Creswell (2010), a estratégia qualitativa de pesquisa dispõe de diversos métodos de investigação. Dentre eles, a pesquisa fenomenológica se apresenta como uma forma de atuação que agrega teoria e método, a partir de uma investigação aprofundada da experiência humana, produzindo um processo de reflexão capaz de captar os significados e sentidos emergentes acerca de um determinado fenômeno (Forghieri, 2004).

À luz de uma perspectiva teórica e metodológica alicerçada na fenomenologia, na qual se entende que a experiência torna-se acessível, primordialmente, pela via da linguagem, função privilegiada que organiza a vivência em formas expressivas singulares (Dutra, 2002), utilizou-se como método a "narrativa" (Benjamim, 1994), com enfoque vivencial (Silva \& Trentini, 2002).

\subsection{Construção dos dados}

Em consonância com os fundamentos teóricos e metodológicos da fenomenologia, a estratégia definida para 
a construção dos dados consistiu na entrevista semiestruturada, de natureza clínica, áudio-gravada, com a seguinte pergunta disparadora Como foi para você a perda do seu filho? Me conte um pouco essa história. A partir dessa primeira interrogação, permitiu-se que a participante se expressasse livremente. Outras questões, de natureza focal, foram também elaboradas e utilizadas a fim de fornecer maior detalhamento acerca das circunstâncias constituintes do luto materno. Tal instrumento, frequentemente utilizado em pesquisas de natureza qualitativa (Belei, Gimeniz-Paschoal, Nascimento \& Matsumoto, 2008), foi escolhido mediante o entendimento de que possibilitaria a construção de uma narrativa sobre o vivido.

Foram respeitadas todas as prerrogativas éticas de pesquisa, tais como a anuência do Comitê de Ética em Pesquisa da UFRN (Parecer n. 246/2012, emitido no dia 25.04.2012) e a assinatura do Termo de Consentimento Livre e Esclarecido, confirmando a aceitação e participação voluntária da mãe. Ainda dentro dos limites éticos, a pesquisa garantiu à participante, ao fim das entrevistas, encontros seguintes com a finalidade de acolher a mãe no tocante às repercussões produzidas pela pesquisa, em face da qualidade específica deste estudo em abordar e mobilizar conteúdos emocionais de grande impacto.

\subsection{Participante}

A pesquisa contou com a participação de uma mãe e foi desenvolvida numa organização não governamental de apoio à criança com câncer, localizada na cidade do Natal-RN. A escolha do local foi demarcada pela reconhecida experiência do serviço junto ao público infanto-juvenil que apresenta o diagnóstico de câncer e doenças hematológicas crônicas, bem como pela disponibilidade de um projeto que tem como finalidade o acompanhamento a familiares enlutados de crianças e adolescentes que foram assistidos durante o tratamento pela instituição. O processo de seleção da participante ocorreu mediante consulta prévia a uma lista de mães que se adequavam ao perfil requerido pela pesquisa, de acordo com os critérios de inclusão, a saber: a) mães adultas (com idade igual ou superior a 18 anos) que perderam seus filhos por câncer infantil; b) mães de crianças que antes de morrer tenham enfrentado no mínimo seis meses de tratamento oncológico e c) mães indicadas por um profissional pertencente à equipe técnica da instituição.

\subsection{Análise dos dados}

A proposta de análise da narrativa utilizada neste trabalho consistiu numa variante inspirada nos passos propostos por outros pesquisadores (Amatuzzi, 2009;
Giorgi 1985, Szymanski, 2002), contemplando a execução de cinco etapas. A primeira delas consiste na transcrição do material áudio-gravado para a composição do texto de referência, sendo este produzido a partir do conteúdo obtido dos procedimentos metodológicos em sua totalidade, incluindo informações advindas não apenas da fala (stricto sensu), mas também o registro de diversos outros aspectos relacionados ao contexto de pesquisa, à conjuntura situacional do pesquisador e à relação entre entrevistador e entrevistado. O segundo passo da análise compreende a leitura do texto de referência. Nesta fase, o pesquisador acessa a experiência no modo escrito, quantas vezes se mostrar necessário, visando à obtenção de familiaridade com o material. Havendo-se apreendido o sentido do todo, no terceiro momento cabe ao pesquisador delimitar as unidades preliminares e emergentes de sentido, em função do fenômeno que está sendo investigado. Cumprida essa etapa, segue-se com a composição de eixos temáticos, nos quais se agregam as unidades de sentido conforme as relações de similaridade que apresentam entre si. Por fim, realiza-se uma síntese compreensiva da experiência. Posteriormente à consecução dos cinco momentos acima descritos, os resultados apreendidos são discutidos à luz dos conceitos de "cuidado", "ser-para-a-morte" e "temporalidade", dentre outros instituídos pela hermenêutica existencial heideggeriana. Em semelhança ao referencial heideggeriano, que pressupõe o ser humano como um processo inacabado e em constante movimento, este trabalho procura igualmente "outras possibilidades de autointerpretação da vida" (Casanova, 2009, p. 51), por meio de novas redes significativas em torno do fenômeno do luto, sem que haja um radical extermínio dos posicionamentos tradicionais.

\section{Resultados e discussão: a experiência de Maria}

Uma vez finalizada a fase de análise da entrevista, foi possível construir a "experiência de Maria”. Este nome foi escolhido simbolicamente para representar a participante do estudo. De forma semelhante, outros nomes fictícios foram utilizados na exposição da sua história para preservar a sua identidade e de sua filha.

Maria, 37 anos, nível de escolaridade fundamental completo, renda mensal familiar de um salário mínimo, é uma mulher casada, dona de casa, que teve seis filhos, dentre eles Júlia, que foi diagnosticada com leucemia quando estava prestes a fazer cinco anos e, após quatro anos e oito meses de tratamento, aos nove anos de idade, faleceu. Decorrido um ano e três meses da morte da filha, ela foi convidada e concordou em participar desta pesquisa compartilhando sua experiência em relação ao adoecimento e morte de Júlia.

Compreendendo a narrativa produzida no encontro entre narrador e ouvinte como uma história que oferece uma totalidade descritiva, afetiva e significativa de 
uma determinada experiência, foi possível vislumbrar 9 unidades de sentidos emergentes, as quais puderam ser agregadas em três grandes eixos temáticos: história prévia, adoecimento infantil e suas repercussões; a rede de apoio e o cuidado; e a perda e o depois: enfrentamento e significação.

\subsection{História prévia, adoecimento infantil e suas reper- cussões}

\subsubsection{Envolvimento materno durante o tratamento do câncer infantil}

No caso de Maria, evidencia-se uma relação mãe-filha que, mesmo antes do adoecimento, era marcada por forte envolvimento. Com o advento do adoecimento e o diagnóstico de leucemia, esta relação se estreita ainda mais, de modo que Maria volta-se quase que exclusivamente para os cuidados com a filha, distanciando-se de seus outros papéis. Mesmo diante da possibilidade de dividir responsabilidades com outras pessoas, entre elas familiares, Maria opta por assumir a integralidade dos cuidados de sua filha, demonstrando uma escolha autêntica, no que se refere à autoria do cuidado. Por outro lado, verifica-se que o exercício do cuidado por parte desta mãe sugere uma forma indissociada de estar-no-mundo-com-sua-filha-com-câncer, conforme desvelado nas falas que seguem:

Aí veio a descoberta da doença dela. Aí foi que se juntou mais, eu e ela. (...) Ela tem outros parentes, mas eu não queria, eu queria estar presente em tudo. Então, eu não deixava as outras pessoas chegarem perto. Então, meu mundo foi só voltado para ela.

Quando ela foi para UTI eu fiquei imaginando, se eu perder, o que vai ser de mim, porque eu só sei fazer aquilo que Júlia faz... Levar ela para fazer quimioterapia, para fazer exame, para se consultar, para vir para casa de apoio e outras e outras coisas.

Critelli (2007), referindo-se ao cuidado, assinala que este não é aleatório. Na perspectiva ontológica e relacional que Heidegger atribui ao Cuidado, ele o afirma como uma condição constituinte da existência (Silva, 2006). Nesse sentido, na experiência de coexistência com outros entes (semelhantes ou diferentes) no mundo, o Dasein encontra-se disposto a e expresso em dois tipos de cuidado: o modo da ocupação, no qual se percebe uma primazia da relação utilitária; e o da preocupação, típico da relação entre Daseins (Pala, 2008). Sobre este último modo de cuidado, Heidegger acentua ainda outra diferenciação entre o modo de preocupação substitutiva dominadora, que remete a uma atitude de substituição (de fazer pelo outro), como o próprio nome já define; e a preocupação antepositva liberadora que, visando à liberdade do outro, permite ao mesmo o esclarecimento de suas possibilidades e o domínio na realização do cuidado para consigo mesmo (Heidegger, 1927/2005).

Utilizando-se deste referencial como um horizonte de reflexão e retornando ao depoimento de Maria, é possível observar que o cuidado dispendido por ela na relação estabelecida com a sua filha durante o adoecimento, embora autêntico e legítimo, uma vez que foi conscientemente eleito por ela, restringiu, por outro lado, suas possibilidades de ser-no-mundo durante o tratamento. Frente à fragilidade da filha, desvela-se a predominância de um modo de preocupação susbstitutivo. Todas as suas atividades estavam circunscritas ao contexto de necessidade da filha, de forma que o progressivo agravamento da doença e a consequente iminência de perdê-la retirava-lhe qualquer possibilidade de atribuir sentido futuro a sua própria existência.

\subsubsection{A mãe e o diagnóstico de câncer infantil}

Quando solicitada a relatar sobre o momento do diagnóstico, Maria faz menção à existência de um "erro médico" na história da doença da filha, sugerindo que a patologia foi descoberta e confirmada tardiamente. Após um período de dúvidas e suspeitas, a comunicação do diagnóstico é finalmente ratificada pela médica da criança soando como o anúncio de um evento de elevada gravidade.

Ela fez o mielograma e veio a confirmação que ela estava com leucemia. (...) Eu procurei um buraco, infelizmente eu não achei. Tudo desabou na minha cabeça. Tudo, tudo, tudo, tudo. Porque a gente pensa que nada vai acontecer com a gente, só acontece com os outros, né? Nunca imagina que vai acontecer com a gente. Principalmente uma doença dessa para uma criança de quatro anos.

A constatação do câncer da filha, expressa na procura urgente por um "buraco", produz uma clara tentativa de escapar ao contato com a notícia, bem como com todo o resto que a mesma poderia representar prospectivamente. Mesmo diante de uma intensa busca por um caminho que pudesse ocultar ou mesmo eliminar o adoecimento da filha, Maria enxerga-se sem saída, rendendo-se, portanto, ao impacto emocional desta conclusão.

É possível perceber que o primeiro contato com a doença e o seu progressivo agravamento evidenciam-se como episódios nos quais o sentido e o peso da morte assumem sua face mais nítida, da qual a fuga e o distanciamento tornam-se ações impraticáveis (Pompeia \& Sapienza, 2011). A afetação provocada pela notícia, expressa principalmente pela via do choro e por uma avalanche de apreensões que lhe invadem o pensamento, 
parecem fazer alusão à esquecida, porém real condição de desamparo humano.

De acordo com Heidegger (1927/2005), o Dasein consiste no ser que existe na facticidade de estar lançado-no-mundo, aberto às condições de liberdade e responsabilidade perante as suas escolhas. No universo da cotidianidade, dominado pelo discurso "do a gente", o homem age sob a pretensa certeza de que seus planos encontram-se edificados em bases sólidas. Consumido pela atraente, porém delicada imagem de "estabilidade da vida", ele não põe em perspectiva a sua condição finita, comportando-se como se nada pudesse obstaculizar a concretização dos projetos. Neste cenário de ilusória permanência das coisas e das pessoas, a experiência de Maria diante do diagnóstico de câncer de sua filha parece funcionar como um fenômeno que a constrange de tal forma que lhe retira o antigo sentimento de sossego e serenidade, relembrando-lhe uma das principais características que regem a vida e que, frequentemente, costuma ser ignorada: a transitoriedade.

Partindo desta vivência compartilhada por Maria, pode-se apreender que o encontro com a doença oncológica, retira o homem da comum convivência coletiva na qual imperam significados generalizados e impessoais; e manifesta a ontológica sensação de desamparo humano diante do mundo, confirmando a frágil, inóspita e precária condição da vida (Spanoudis, 1981).

\subsubsection{Tratamento: "parte feliz e parte triste"}

Maria refere-se ao período de tratamento da filha como triste e feliz. Apesar de admitir ter vivido momentos difíceis e dolorosos, ela reconhece igualmente a ocorrência de eventos positivos. Quanto a isto, menciona que Júlia conviveu com pessoas boas e que, a despeito da dor, foi também uma fase na qual a filha pôde viver novas e gratificantes experiências.

O tratamento foi difícil, foi doloroso, mas teve a parte feliz e a parte triste. (...) Durante esses quatro anos e oito meses, ela conviveu com pessoas boas, ela conheceu lugares bons, ela viajou, ela foi para o Rio, ela participou do Criança Esperança, ela saiu em revista. Foi uma fase dolorosa? Foi. Mas foi uma fase boa para ela. De ela ter participado disso tudo. Apesar da doença, de ser furada, de perder veia, de ter pegado bactéria no cateter, de ter sentido dor, de ter tomado morfina de meia em meia hora, para aliviar a dor, mas para ela, ela foi feliz. Para ela, era tudo. A Casa [de apoio] era tudo para ela. Ela foi feliz e eu também.

Mesmo diante de uma experiência tão traumática, como parece ser aquela expressa por Maria, é possível notar que ela consegue visualizar e, acima disso, valo- rizar os ganhos em detrimento da perda. Sobre esta atitude positiva de abertura na compreensão simultânea dos ganhos e perdas de um determinado acontecimento, Kovács (1996) confirma:

nas situações "dolorosas”, em que por algum tempo se vive sob o domínio da dor, do sofrimento, em alguns momentos percebidos como sem saída, como só a morte se configuraria como tal, podem ocorrer reviravoltas, transformações - e da morte emerge uma nova vida com mais vigor. (p. 13)

\subsection{Rede de apoio e o cuidado}

\subsubsection{Relação com os outros filhos}

No tocante à relação com os outros filhos, destacam-se em sua narrativa a filha primogênita e os filhos mais novos (gêmeos). Com a primeira, que lhe ajudou no período de adoecimento de Júlia, ela demonstra ter uma relação de proximidade e gratidão. $\mathrm{O}$ compartilhar da experiência de sofrimento e perda parece, portanto, tê-las aproximado.

Os filhos gêmeos, por outro lado, surgem na vida de Maria para concretizar a tentativa de um transplante de medula para Júlia. Diante da incompatibilidade na família, a médica da criança sugere que Maria engravide rapidamente como alternativa para tentar salvar a filha. Ela aceita o conselho da médica, retira o Dispositivo Intrauterino (DIU) e engravida. Entretanto, mesmo após o nascimento dos gêmeos, Maria não direciona seus cuidados aos recém-nascidos, delegando essa atribuição aos familiares. A respeito dessa última gestação, Maria relata:

Eu fiquei meio assim, porque eu não queria engravidar, eu queria logo achar um doador para ela. Eu queria achar um doador que era para eu cuidar dela. E se eu engravidasse, não podia fazer o acompanhamento; e se ela fosse para o transplante, eu não podia ir porque eu ia dar de mamar, eu ia estar de resguardo, entendeu? Eu não ia participar disso tudo. E eu queria participar, né?

Nem tomar conta dos gêmeos eu sabia tomar direito; eu num dava banho, eu não trocava uma fralda, eu não fazia o comer deles, eu não fazia nada porque era só voltada pra Júlia. Os gêmeos nasceram, mas meu problema era Júlia, sabe? O meu problema era só Júlia.

Conforme o último trecho exposto, é possível refletir a respeito de que saber Maria se refere quando afirma que não sabia tomar conta dos gêmeos. Como mãe de quatro filhos, antes deles, Maria dispunha de um conhecimento 
prático, adquirido na relação com cada filho, nas gestações anteriores. Na conjuntura que se configura para o exercício dos cuidados primários com os gêmeos, Maria parece falar, não do saber tácito ou intelectual, mas de uma disponibilidade para cuidar, que, naquele momento, estava dirigida exclusivamente para Júlia.

De acordo com Heidegger (1927/2005), a condição ontológica do homem de estar aberto a diversas possibilidades está, necessariamente, associada a uma disposição prévia. Nesse sentido, o homem sempre se encontra afetado na sua relação com o mundo. Sabendo-se que a estrutura ontológica da disposição pode ser expressa por inúmeros estados de ânimo, é possível constatar que a história de Maria apresenta-lhe uma encruzilhada: como cuidar simultaneamente da filha doente e dos filhos recém-nascidos? Maria escolhe priorizar o cuidado à filha e não demonstra arrependimento pela decisão tomada, ainda que tenha sofrido quando precisou escolher. Somente com a morte de Júlia, Maria mostra-se disponível para dedicar-se aos gêmeos e encontrar outros sentidos nesta relação.

É por isso que hoje em dia meu mundo é voltado só pra eles dois. (...) Tudo que eu fazia com Júlia eu faço com eles. Tudo é voltado pra eles, meu mundo é voltado pra eles. Que é o que me cobre, hoje em dia, são eles dois; que a minha alegria é só eles dois, por isso que eu não tenho tristeza, graças a Deus.

Há que se fazer uma ressalva significativa acerca de um trecho do recorte da fala de Maria, anteriormente destacado. Ao falar - "é o que me cobre" - ela parece sugerir que, hoje, os dois filhos mais novos assumem um sentido de cobrir (velar) a sua tristeza. Para Heidegger, a verdade do Dasein se expressa por meio de inconstantes movimentos alternados de desvelamento e encobrimento, nunca permanecendo exclusivamente numa dessas formas (Inwood, 2000). Tais oscilações, por sua vez, encontram morada significativa por meio da linguagem, que comunica e revela as contradições e tensões do Ser (Augras, 2011).

Tomando essas considerações como horizonte interpretativo, é possível notar que ao mesmo tempo em que o conteúdo narrativo de Maria expressa sentimentos positivos relacionados ao seu papel de mãe, hoje, direcionados aos filhos mais novos, este mesmo envolvimento com os gêmeos parece esconder o seu modo de ser mais próprio e pessoal.

Percebe-se ainda que, desde a morte de Júlia, houve uma transferência do cuidado para os filhos, observando-se reminiscências no modo de prover esse cuidado. Nesse deslocamento, Maria dá sinais de que sua relação com os gêmeos ainda está fortemente referendada na experiência materna anterior. Tudo que é realizado para eles, segue o modelo de atitudes e ações antes dirigido a Júlia. O sentido de imprecisão que emerge acerca do lu- gar desses dois novos filhos na vida de Maria desvela-se, por ora, na ausência de identificação pessoal dos filhos. Em momento algum, ela os nomeia individualmente, restando a eles o genérico lugar "dos gêmeos".

\subsubsection{O silêncio, a escuta e a palavra frente à dor materna}

Durante o período da doença de Júlia, houve aproximação e auxílio no cuidado à criança e no suporte necessário para que a mãe pudesse cuidar da filha. Com a morte de Júlia, entretanto, o sentimento de Maria é que todos se afastaram. Hoje, embora a família converse sobre os momentos bons da criança, parece não haver abertura, por parte da mãe, para um diálogo genuíno com os familiares.

Critelli (2007) afirma que a perda de sentido diante da vida gera um sentimento de vazio, do qual muitas pessoas costumam fugir. No caso de Maria, a sua vivência do luto parece não conceder o necessário espaço ao sofrimento. Nesse sentido, ela não autoriza que sensações negativas referentes à perda da filha se sobressaiam diante dela, por terceiros, impedindo, assim, que se configure um espaço de legitimidade de expressão do outro. Pode-se sugerir, portanto, um modo impróprio desta mãe de se haver com o enfrentamento do outro, por meio da tentativa de controlar ou até impedir a tristeza alheia.

É que a família mesmo não toca nesse assunto. (...) Aí, a gente tem que respeitar a vontade deles, (...) quando se junta, aí começa só o choro, porque começa a lembrar dela, sabe? É uma coisa que eu não quero, como eu digo: "lembrar dela com alegria, não com tristeza”. Que ela não gostava de tristeza, só gostava de alegria.

Por outro lado, após um ano e três meses da morte de sua filha, Maria relata a oportunidade de construir diálogos autênticos sobre a ausência de Júlia com a filha primogênita, a psicóloga da casa de apoio e mães que passam/passaram por experiência semelhante a sua. A existência da casa de apoio e a permanente possibilidade de continuar frequentando este local, mesmo após a morte da filha, parecem fazer parte de uma complexa e particular tessitura de relações nas quais ela consegue se sentir segura o suficiente para poder seguir adiante. Os trechos que ilustram um pouco dessa disponibilidade de Maria são: "Amigo? Eu não tenho amigo. Meus amigos são as mães daqui da casa. Mas, estão na mesma situação, que não perderam o filho, que estão ainda em tratamento, né?"; Eu converso mais com Manu. Prefiro mais com Manu".

A literatura em Psico-oncologia enfatiza que o processo de adoecimento e tratamento do câncer modifica a rotina de atividades da criança e de sua família. A ma- 
neira como este fator poderá interferir em cada grupo familiar dependerá não só da capacidade destes responderem a essa necessidade de adaptação, mas também da extensão (geográfica e funcional) da rede social de apoio que acompanhará cada um desses sujeitos (Di Primio \& cols., 2010). Nesse sentido, a narrativa de Maria vai ao encontro dos resultados demonstrados por estudos que elegem a família pessoal, outras famílias com problemática semelhante e profissionais de saúde, como suportes privilegiados na situação do câncer infantil (Beltrão \& cols., 2007). Acredita-se que, por compactuarem de experiências semelhantes, ou por conviverem com a realidade do adoecimento cotidianamente, as mães encontram conforto e aceitação nestes atores ao longo de qualquer período do adoecimento.

\subsubsection{A equipe de saúde e o cuidado}

Para além do contexto primário de relações, cabe um destaque às marcas deixadas pelos profissionais de saúde neste cenário de adoecimento, tratamento e morte. No que se refere à assistência à saúde da criança com câncer, estudos empreendidos neste campo posicionam-se a favor da recomendação de uma equipe multidisciplinar que seja capaz de oferecer, em conjunto, um cuidado (de ordem técnica e subjetiva) global que alcance a criança e seu entorno familiar (Di Primio \& cols., 2010; Matsumoto, 2009). Sob a ótica do cuidado desempenhado pelos profissionais de saúde ao longo de todo tratamento de sua filha, Maria refere ausência total de queixas.

Eu não tenho do que reclamar da Liga. Do SUS, principalmente. Ele cobriu tudo que minha filha precisou. Eram quatro médicos, eram duas enfermeiras, eram bastante técnicos. Tinha Camila também. Eu não tenho o que reclamar. Eu só tenho que agradecer. Porque o que eles fizeram por minha filha, não tem dinheiro nesse mundo que pague.

Neste amplo contexto de implementação de cuidados, Heidegger compreende o adoecimento (físico e psíquico) como uma limitação do exercício de estar consigo mesmo e com os outros de forma fluida (Nogueira, 2008), portanto, requerendo um suporte externo. Em consonância com esta perspectiva e considerando a aplicabilidade do exercício deste cuidado no contexto da Saúde, Ayres (2004) conclama uma disposição interessada para escutar o outro a fim de que a comunicação ultrapasse o discurso tecnocientífico e alcance a narrativa histórica do sujeito, produzindo um diálogo autêntico. Conforme essas referências, pode-se admitir que a equipe profissional que acompanhou o caminho do adoecimento da filha de Maria propiciou a existência desse encontro genuíno.

\subsection{A perda e o depois: enfrentamento e significação da perda}

\subsubsection{A experiência de morte da filha}

De acordo com sua narrativa, a vivência da morte de Júlia parece ter se processado de maneira gradual para Maria. Embora a notícia do óbito implique tristeza, os dois episódios que assinalam a recidiva da doença são escolhidos por ela como os piores momentos (até hoje), desde o diagnóstico da doença.

Eu sabia que estava bem próximo, eu sabia que os médicos estavam levando ela pela qualidade de vida dela, eu sabia que um dia ia chegar. Eu fazia de conta que não queria que esse dia chegasse, mas ia chegar.

A princípio, os sentidos atribuídos ao momento que sucede ao da morte revelam posturas de respeito e aceitação. Embora inserida no contexto hospitalar, espaço este reconhecido por uma forma técnica de tratar a morte, o fim da vida da filha de Maria foi respeitado e, diante dele, estabelecido um cuidado individualizado, auxiliado pela presença da psicóloga que pôde testemunhar junto a ela a partida da filha. Sobre esse modo diferenciado de estar diante da morte do outro, Sá (2010) afirma que a diminuição da exigência para promover uma adequação a regras, permite um sofrimento "no modo reverencial”, condição esta que só se torna possível porque somos ser-com.

Ela ficou no isolamento, da hora que ela entrou - na segunda-feira - ela ficou no isolamento até a hora de chegar o caixão dela. Ela ficou no isolamento, fecharam a porta, me deixaram sozinha lá com ela. Ficou eu e Manu, dentro de um quarto. Ela não foi para aquele saco, que botam. Ela não foi para Necrotério. Ela não foi para canto nenhum. Ela ficou todo tempo comigo, no quarto até chegar o caixão, o pessoal da funerária para levar ela para o velório.

Mesmo consciente da ausência de vida da filha, Maria exige consideração sobre aquele corpo que não mais dispunha daquela qualidade. Embora reconhecesse que a história de sua filha chegava ao fim naquele momento, não demandando mais seu auxílio no tocante ao aspecto do adoecimento, Maria requisitava ações que respeitassem a existência da filha. Nesse sentido, a mera manipulação era intensamente rejeitada, pois corresponderia ao cuidado impessoal com a filha, como se ela se tornasse mais um caso. Sobre essa particularidade da natureza do cadáver, Heidegger (1927/2005) lembra que este apresenta um status intermediário - "algo que perdeu a vida” (p. 18) - daí advém a particularidade dos gestos dirigidos a ele, que nem satisfaz o modo anterior que existia no período de vida, mas também não atende ao modo direcionado aos entes simplesmente dados, ou seja, coisas e instru- 
mentos. A atitude da psicóloga e o consentimento do hospital, neste caso, parecem ter refletido um compromisso com a singularidade.

\subsubsection{Não há o que dizer...}

Ao ser questionada sobre o que diria a mães que passam hoje pelo que ela passou - doença e morte de um filho, Maria responde:

Existe a cura. Infelizmente a minha não teve. Mas tem paciente aqui na Casa que está curado. Não vá por fulano, nem por cicrano, nem por beltrano. Pegue seu filho, cuide do seu filho, traga ele para fazer o tratamento dele. Não vá pela cabeça de ninguém. Vá pelo caminho do médico. Mas que existe a cura existe. O negócio é você não desistir. É você lutar com unhas e dentes e correr atrás.

À mãe que perdeu um filho com câncer, Maria afirma não saber o que dizer.

Eu não tenho palavras para dizer nada. Só o tempo que vai lhe dizer. Porque o que eu passei, você está passando. Então, eu não sei o que lhe dizer. (...) Vai dizer o quê? Vai dizer “Se acalme, se controle?”. Não. É difícil ter que falar alguma coisa para uma mãe que perde o filho.

Ela tem, entretanto, o compartilhar de uma experiência de dor. "O que você tá passando, eu tô passando"; "A dor que ela tá passando, eu até hoje passo". A experiência da morte da filha pelo câncer infantil parece produzir duas formas de se reportar ao mundo. Às mães que se veem diante da mesma tarefa que ela atravessou no passado - cuidado a um filho com câncer, ela dirige uma mensagem de esperança, uma crença na possibilidade da vida. A experiência de perda, embora assinalada por marcas de sofrimento, parece não ter abalado a sua confiança na vida. Para aquelas, entretanto, que precisam enfrentar a perda do filho, parece não haver o que dizer. Neste último caso, o silêncio impera diante da palavra e, ainda assim, se faz discurso. Sobre a particularidade deste modo de expressão, Heidegger afirma que "silenciar em sentido próprio só é possível num discurso autêntico. Para poder silenciar, a pre-sença deve ter algo a dizer, isto é, deve dispor de uma abertura própria e rica de si mesma" (Heidegger, 1927/2005, p. 224).

\subsubsection{A doença e a morte ressignificando a vida: o desvelamento de novos sentidos}

A despeito do intenso sofrimento e das grandes transformações ocorridas em sua vida, pode-se perce- ber que o adoecimento e a morte da filha ressignifica alguns aspectos da vida desta mãe. Determinados sentidos parecem se reafirmar, como por exemplo, o lugar central que a maternidade ocupa em sua vida. Outros, entretanto, parecem se desvelar, como a valorização da vida, acima de qualquer dificuldade. Imediatamente após a perda da filha, Maria se questiona sobre sua própria vida. A morte, como um fenômeno da vida, paralisa a vida desta mulher, incitando-lhe um processo de reflexão, de busca, de construção de sentidos que pudessem conduzi-la na continuidade da sua existência. Ver o sofrimento do outro ajudou a mãe a mudar sua perspectiva frente à vida:

Ser mais humilde, que eu não era. A crescer mais. Dar valor mais à vida. Eu reclamava demais da vida e hoje em dia eu não reclamo. Para mim é tudo bom. Pra mim é tudo ótimo. Nem no momento em que Júlia se foi, eu reclamei. Eu aprendi isso, que a gente não pode reclamar da vida. No período da doença e depois de Júlia, que eu perdi Júlia.

De acordo com Heidegger (1927/2005), o Ser é formado por três modos constitutivos e igualmente originários entre si: a disposição, a compreensão e o discurso. Na compreensão, o Dasein funda a possibilidade permanente de significar o mundo, tal como este se desvela, ou seja, de elaborar um sentido. Sentido, sob a interpretação ontológico-existencial heideggeriana, é concebido, portanto, como "aquilo que pode articular-se na abertura da compreensão" (Heidegger, 1927/2005, p. 208), admitindo direcionamentos múltiplos e diversos. Transportando-se novamente para a experiência de Maria, pode-se notar que a sua narrativa demonstra um redimensionamento das dificuldades. A morte da filha, na conjuntura que foi vivenciada, ofereceu outro olhar às vicissitudes da vida, permitindo a ela uma nova leitura diante das situações que, outrora, lhe apareciam como entraves, produzindo um novo enfrentamento de sua parte.

\section{Considerações finais}

A história de Maria ajuda-nos a problematizar o luto materno como uma experiência que se desenrola de maneira particular, auxiliando-nos a ampliar a compreensão dos significados e sentidos atribuídos ao fenômeno da morte de um filho por câncer infantil. Inicialmente, a síntese desta experiência desvela que o diagnóstico de câncer infantil, como possibilidade da concretização da morte, impõe-se abruptamente na vida da mãe, afastando-a imediatamente do modo de ser constitutivo na impessoalidade. Embora surja de forma drástica e indesejada, o adoecimento infantil, neste caso, permite à mãe um redimensionamento na sua forma de existir no mundo, possibilitando proximidade com o seu modo de ser mais 
próprio. Nas circunstâncias do câncer infantil, o cuidado dirigido pela mãe à criança se expressou predominantemente no modo da preocupação substitutiva, em vista, sobretudo, da etapa de desenvolvimento do sujeito afetado e da fragilidade desencadeada pelo tratamento, não havendo valorações negativas sobre essa forma de proceder. Por fim, há de se chamar atenção para o relevante papel da equipe de saúde no acompanhamento destas mulheres. A narrativa desta experiência oferece sinais de uma repercussão positiva da rede de apoio frente ao processo de luto materno, confirmando os dados da literatura que destacam esse suporte como fator de proteção para mães que vivem a experiência de adoecimento e morte de um filho.

\section{Referências}

Amatuzzi, M. M. (2009). Psicologia fenomenológica: uma aproximação teórica humanista. Estudos de Psicologia (Campinas), 26(1), 93-100.

Ariès, P. (1977). História da morte no ocidente. (P. V. Siqueira, Trad.) Rio de Janeiro: Ediouro. (Trabalho original publicado em 1975)

Augras, M. (2011). O Ser da compreensão - fenomenologia da situação de psicodiagnóstico (14a ed.). Petrópolis: Vozes.

Ayres, J. R. C. M. (2004). O cuidado, os modos de ser (do) humano e as práticas em saúde. Saúde e Sociedade, 13(3), 16-29.

Beck, A. R. M. \& Lopes, M. H. B. M. (2007). Cuidadores de crianças com câncer: aspectos da vida afetados pela atividade de cuidador. Revista Brasileira de Enfermagem, 60(6), 670-675.

Belei, R. A., Gimeniz-Paschoal, S. R., Nascimento, E. N. \& Matsumoto, P. H. V. R. (2008). O uso de entrevista, observação e videogravação em pesquisa qualitativa. Cadernos de Educação, 30, 187-199.

Bellato, R. \& Carvalho, E. C. (2005). O jogo existencial e a ritualização da morte. Revista Latino-americana de Enfermagem, 13(1), 99-104.

Beltrão, M. R., Vasconcelos, M. G., Pontes, C. M. \& Albuquerque, M. C. (2007). Câncer infantil: percepções maternas e estratégias de enfrentamento frente ao diagnóstico. Jornal de Pediatria, 83(6), 562-566.

Benjamin, W. (1994). Obras escolhidas: magia e técnica, arte e política (7a ed.). São Paulo: Brasiliense.

Bowlby, J. (2004). Apego e perda: perda: tristeza e depressão (Vol. 3). São Paulo: Martins Fontes (originalmente publicado em 1985).

Carneiro, D. M. S., Souza, I. E. O. \& Paula, C. C. (2009). Cotidiano de mães acompanhantes-de-filhos-que-foram-a-óbito. Escola Anna Nery Revista de Enfermagem, 13(4), 757-62.

Casanova, M. A. (2009). Compreender Heidegger. Petrópolis: Vozes.
Creswell, J. W. (2010). Métodos qualitativo, quantitativo e misto (3a ed.). Porto Alegre. Artmed.

Critelli, D. M. (2007). Analítica do sentido: uma aproximação e interpretação do real de orientação fenomenológica. São Paulo: Brasiliense.

Di Primio, A. O., Schwartz, E., Bielemann, V. L. M., Burille, A., Zilmer, J. G. V. \& Feijó, A. M. (2010). Rede social e vínculos apoiadores das famílias de crianças com câncer. Texto Contexto Enfermagem, 19(2), 334-342.

Dutra, E. (2002). A narrativa como uma técnica de pesquisa fenomenológica. Estudos de Psicologia (Natal), 7(2), 371-378.

Elias, N. (2001). A solidão dos moribundos seguido de envelhecer e morrer. Rio de Janeiro: Jorge Zahar.

Forghieri, Y. C. (2004). Psicologia Fenomenológica: fundamentos, método e pesquisa. São Paulo: Thomson Pioneira.

Franco, M. H. P. (2009). Luto em cuidados paliativos. In Conselho Regional de Medicina do Estado de São Paulo (org.), Cuidados Paliativos, Cadernos Cremesp (pp. 559570). São Paulo: Autor.

Giorgi, A. (1985). Phenomenology and psychological research. Pittsburg: Duquesne University Press.

Heidegger, M. (2005). Ser e Tempo - Partes I e II (15a ed.). Petrópolis: Vozes (originalmente publicado em 1927).

Hoffmann, L. (1993). A morte na infância e sua representação para o médico: reflexões sobre prática pediátrica em diferentes contextos. Cadernos de Saúde Pública, 9(3), 364-374.

Instituto Nacional de Câncer José Alencar Gomes da Silva INCA - Ministério da Saúde (2011). Estimativa 2012: incidência de câncer no Brasil. Rio de Janeiro: Autor.

Inwood, M. (2000). Heidegger. São Paulo: Edições Loyola.

Kovács, M. J. (1996). A morte em vida. In M. H. P. F. Bromberg, M. J. Kovács, M. M. M. J. Carvalho \& V. A. Carvalho (orgs.), Vida e morte: laços da existência (pp. 11-33). São Paulo: Casa do Psicólogo.

Matsumoto, D. Y. (2009). Cuidados paliativos: conceitos, fundamentos e princípios. In Academia Nacional de Cuidados Paliativos (org.), Manual de cuidados paliativos (pp. 321-330). Rio de Janeiro: Diagraphic.

Minayo, M. C. S. (2000). O desafio do conhecimento: pesquisa qualitativa em saúde. São Paulo: Hucitec, Rio de Janeiro: Abrasco.

Nogueira, R. P. (2008). Stress e padecimento. Comunicação Saúde Educação, 12(25), 283-293.

Ortiz, M. C. M. (2003). À margem do leito: a mãe e o câncer infantil. São Paulo: Arte \& Ciência.

Pala, Á. C. S. (2008). O cuidado psicológico com doentes crônicos em uma perspectiva fenomenológica existencial. Dissertação de Mestrado, Universidade Federal Fluminense, Niterói. 
Parkes, C. M. (1998). Luto: Estudos sobre a perda na vida adulta. (M. H. P. Franco, Trad.) São Paulo: Summus. (Trabalho original publicado em 1972)

Pompeia, J. A. \& Sapienza, B. T. (2011). Os dois nascimentos do homem: escritos sobre terapia e educação na era da técnica. Rio de Janeiro: Via Verita.

Sá, R. N. (2010). A analítica fenomenológica da existência e a psicoterapia. In A. M. L. C. Feijó (org.), Tédio e Finitude: da Filosofia à Psicologia (pp. 177-199). Belo Horizonte: Fundação Guimarães Rosa.

Santos, L. M. P. \& Gonçalves, L. L. C. (2008). Crianças com câncer: desvelando o significado do adoecimento atribuído por suas mães. Revista de Enfermagem, 16(2), 224-229.

Silva, D. G. V. \& Trentini, M. (2002). Narrativas como técnica de pesquisa em enfermagem. Revista Latino-americana de Enfermagem, 10(3), 423-432.

Silva, L. C. (2006). O sentido do cuidado na vivência da pessoa com câncer: uma compreensão fenomenológica. Tese de Doutorado, Universidade de São Paulo, Ribeirão Preto.

Spanoudis, S. (1981). Apresentação. In Heidegger, M. (org.), Todos nós... ninguém: um enfoque fenomenológico do social (pp. 9-22). São Paulo: Moraes.

Szymanski, H. (org.). (2002). A entrevista na pesquisa em educação: a prática reflexiva. Brasília: Plano.

Teles, S. S. (2005). Câncer infantil e resiliência: investigação fenomenológica dos mecanismos de proteção na díade mãe-criança. Dissertação de Mestrado, Universidade de São Paulo, Ribeirão Preto.

Wegner, W. \& Pedro, E. N. R. (2010). Os múltiplos papéis sociais de mulheres cuidadoras-leigas de crianças hospitalizadas. Revista Gaúcha de Enfermagem, 31(2), 335-142.

Patricia Karla de Souza e Silva - Psicóloga Clínica, Especialista em Psicologia da Saúde e Mestre em Psicologia pelo Programa de Pós-Graduação em Psicologia da Universidade Federal do Rio Grande do Norte. Endereço Institucional: Rua Praia de Areia Branca, 8936. Ponta Negra. Natal, RN. CEP: 59.094-450.E-mail:patriciakssilva@gmail.com

Symone Fernandes de Melo - Psicóloga Clínica, Doutora em Psicologia Cognitiva pela Universidade Federal de Pernambuco e Docente do Departamento de Psicologia da Universidade Federal do Rio Grande do Norte. Endereço institucional: Universidade Federal do Rio Grande do Norte, Centro de Ciências Humanas, Letras e Artes. Departamento de Psicologia, Campus Universitário. s/n - Lagoa Nova. Natal, RN. CEP: 59.078-970. E-mail: symelo@gmail.com

Recebido em 14.04 .13 Primeira Decisão Editorial em 06.07.13 Aceito em 12.09.13 